ERRATUM

doi:10.1038/nature09949

\title{
Extended megadroughts in the southwestern United States during Pleistocene interglacials
}

Peter J. Fawcett ${ }^{1}$, Josef P. Werne ${ }^{2,4,5}$, R. Scott Anderson ${ }^{6,7}$, Jeffrey M. Heikoop ${ }^{8}$, Erik T. Brown ${ }^{3}$, Melissa A. Berke ${ }^{3}$, Susan J. Smith ${ }^{7}$, Fraser Goff ${ }^{1}$, Linda Donohoo-Hurley ${ }^{1}$, Luz M. Cisneros-Dozal ${ }^{8}$, Stefan Schouten ${ }^{9}$, Jaap S. Sinninghe Damsté $^{9}$, Yongsong Huang ${ }^{10}$, Jaime Toney ${ }^{10}$,

Julianna Fessenden ${ }^{8}$, Giday WoldeGabriel ${ }^{8}$, Viorel Atudorei ${ }^{1}$, John W. Geissman ${ }^{1}$ \& Craig D. Allen ${ }^{11}$

${ }^{1}$ Department of Earth \& Planetary Sciences, University of New Mexico, Albuquerque, New Mexico 87131, USA. ${ }^{2}$ Large Lakes Observatory and Department of Chemistry and Biochemistry, University of Minnesota Duluth, Duluth, Minnesota 55812, USA. ${ }^{3}$ Large Lakes Observatory and Department of Geological Sciences, University of Minnesota Duluth, Duluth, Minnesota 55812, USA. ${ }^{4}$ Centre for Water Research, University of Western Australia, Crawley, Western Australia 6009, Australia. ${ }^{5}$ WA-Organic and Isotope Geochemistry Centre, Curtin University of Technology, Bentley, Western Australia 6845, Australia. ${ }^{6}$ School of Earth Sciences and Environmental Sustainability, Northern Arizona University, Flagstaff, Arizona 86011, USA. ' Laboratory of Paleoecology, Bilby Research Center, Northern Arizona University, Flagstaff, Arizona 86011, USA. ${ }^{8}$ Earth and Environmental Sciences Division, EES-14Los Alamos National Laboratory, Los Alamos, NewMexico 87545, USA. ${ }^{9}$ NIOZ Royal Netherlands Institute for Sea Research, Department of Marine Organic BiogeochemistryPO Box 59, 1790 AB Den Burg,

Netherlands. ${ }^{10}$ Department of Geological Sciences, Brown University, Providence, Rhode Island 02912, USA. ${ }^{11}$ USGS Fort Collins Science Center, Jemez Mountains Field Station, Los Alamos, New Mexico 87544, USA.

Nature 470, 518-521 (2011)

In this Letter, the affiliations for authors Jaime Toney, Julianna Fessenden and Giday WoldeGabriel were listed incorrectly. The correct affiliations for all authors are as shown here. 